\title{
Congenital Neutropenia
}

National Cancer Institute

\section{Source}

National Cancer Institute. Congenital Neutropenia. NCI Thesaurus. Code C61242.

A rare disorder characterized by recurrent infantile infections and absence of neutrophils in the peripheral blood. 